\title{
Effect of Ca or Mg ion irradiation on the bioactivity and strength of hydroxyapatite
}

\author{
Satoshi KOBAYASHI*, Tomomi IZAWA*, Yoshikazu TERANISHI** and Yoshimi OHYABU** \\ * Graduate School of Science and Engineering, Tokyo Metropolitan University \\ 1-1 Minami-Osawa, Hachioji, Tokyo 192-0397, Japan \\ E-mail: koba@tmu.ac.jp \\ ** Tokyo Metropolitan Industrial Technology Research Institute \\ 2-4-10 Aomi, Koto, Tokyo 135-0064, Japan
}

Received: 19 January 2018; Revised: 4 May 2018; Accepted: 24 July 2018

\begin{abstract}
In order to improve bioactivity of hydroxyapatite (HA), the surface of HA was modified with calcium or magnesium ion irradiation. Calcium ion irradiation improved bioactivity of HA up to ion dose $10^{14}$ ions $/ \mathrm{cm}^{2}$, whereas magnesium ion irradiation did not affect bone-like apatite formation. It is found that this different phenomena were attributed to surface electrical potential. Ion irradiation generally induces surface nano-scopic damage, however the strength of HA was not significantly affected by ion irradiation. From cell proliferation, no toxicity of HA irradiated with calcium ions was confirmed. From these results, the effectiveness of calcium ion irradiation on the treatment of bone defect using HA is confirmed.
\end{abstract}

Keywords : Hydroxyapatite, Ion irradiation, Strength, Bone-like apatite formation, Cell proliferation

\section{Introduction}

Bioactive ceramics has high biocompatibility and attracts attention as bone implant materials. Among them, hydroxyapatite $\left(\mathrm{Ca}_{10}\left(\mathrm{PO}_{4}\right)_{6}(\mathrm{OH})_{2}, \mathrm{HA}\right)$ is a main component of natural bone and tooth. HA has bone bonding ability through the bone-like apatite layer, which has similar composition and structure with natural bone, formed on its surface. The bone-like apatite layer is formed by interaction between HA surface and ions in body environment (Kim et al. 2005). The process of apatite layer formation is shown in Fig. 1. When HA is implanted in body environment, first, Ca-rich amorphous calcium phosphate (ACP) is formed by interaction between calcium ion in body environment and HA surface. Secondly, Ca-poor ACP is formed by interaction between Ca-rich ACP and phosphoric ion in body environment. In addition, apatite is formed by interaction between Ca-poor ACP and calcium ion. Apatite formation progresses by crystallization of these ACP layers. Thus, bone-like apatite layer formation could be controlled by the microstructure of HA surface. This fact means that we could provide appropriate bioactivity for HA considering degree and location of disease with surface microstructural modification. There are some methods to modify the microstructure. Among them, ion irradiation is one of the unique techniques to modify the microstructure of HA surface. Various studies have been conducted on ion irradiation for HA ceramics.

Jackierowick et al. (Jaskierowicz et al. 2004) investigated the structural variation in fluorapatite irradiated with C60 cluster ions and found the generation of void or gas filled bubbles. However, they have not clarified whether the surface microstructure consisted of crystal or amorphous solid, which affects the osteoconductive property. Lopatin et al. (Lopatin et al. 1998) used Si ion irradiation method to densify the hydroxyapatite film made on the Si substrates. They reported that samples irradiated reached densities of $83 \%$ of that of fully dense HA and hardness was improved by a factor of 15 . They concluded the advantage of ion-implantation comparing with high temperature sintering was no secondary crystalline phases appearance after densification. Parthiban et al. (Parthiban et al. 2008) investigated the effect of oxygen ion irradiation on the surface structural and osseointegration properties of hydroxyapatite. They reported considerable 
reduction in particle size leading to nanosized HA and better bioactivity of the irradiated samples than that of the HA without irradiation. Pelletier et al. (Pelletier et al. 2004a, b) conducted pulsed laser deposition implantation treated using nitrogen and argon ions to grow HA films. They obtained improvement in hardness, elastic modulus and abrasive wear resistance of HA films after implantation especially for those implanted with nitrogen ions. Miro et al. (Miro et al. 2004) investigated damage in fluorapatite induced by ion irradiation using krypton, iodide and carbon. They confirmed an amorphization of the material. Kobayashi et al. (Kobayashi et al. 2015) conducted low energy ion irradiation on the surface of HA using phosphorous ion. They reported phosphorous ion irradiation decreased bone-like apatite formation whereas improved the adhesion of bone-like apatite layer to HA.

As mentioned above, ion irradiation seems to be a method of controlling the bone-like apatite formation. Considering the bone-like apatite formation process as shown in Fig. 1, calcium ion seems to be effective for the control. In addition, magnesium ion replaces with Ca ion in HA and stabilizes the crystal structure (Kobayashi and Murakoshi 2015). Thus it also seems that $\mathrm{Mg}$ ion is also effective for the bone-like apatite formation.

In this study, bioactivity is defined as bone-like apatite formation ability and a basic property necessary for the bone conductive biomaterials. In order to control the bioactivity of HA, ion irradiation was conducted. Calcium and magnesium ions were used for ion irradiation. The ion was irradiated on HA surface at different ion dose and energy which correspond to ion projected depth. Immersion in simulated body fluid was also conducted to characterize in vitro bioactivity. As a bio-mechanical compatibility, the effect of ion irradiation on the bending strength were measured for HA exposure to simulated body fluid. Toxicity of ion irradiation for cell was also evaluated through cell proliferation.

\section{Soaking Time}

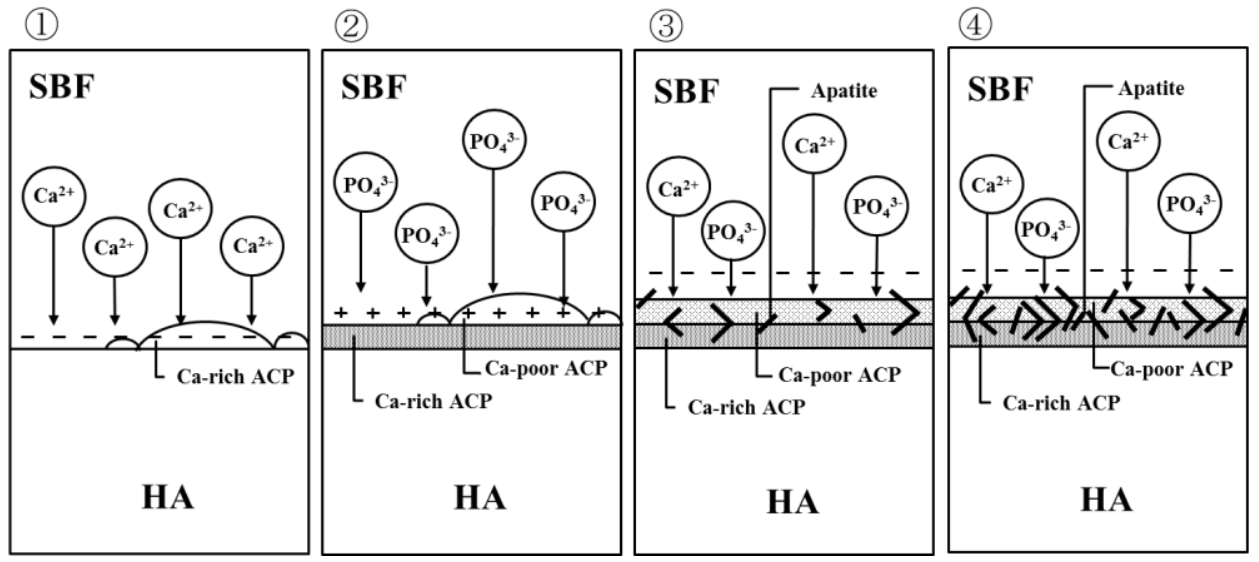

Figure 1 Schematic presentations of the origin of negative charge on the HA surface and the process of bone-like apatite formation thereon in SBF (Kim et al. 2005).

\section{Experimental method}

\subsection{Specimen preparation}

Specimens used for investigation of bioactivity were HA pellets (APP-100, HOYA). Specimen size is $10 \mathrm{~mm} \times 10$ $\mathrm{mm} \times 2.0 \mathrm{~mm}$. Specimens for the investigation of mechanical properties were sintered from HA powder (HA-200, Taihei Chemical) (Kobayashi and Murakoshi 2015). The powder was compacted to $40 \mathrm{~mm} \times 20 \mathrm{~mm} \times 5 \mathrm{~mm}$ green body in a mold die with a press machine (UH-100kNIR, Shimadzu) at holding pressure $98.8 \mathrm{MPa}$ for 1 min. The green bodies were sintered in an electric furnace at temperature $1250{ }^{\circ} \mathrm{C}$ for 5 hours. Heating and cooling rate were $10^{\circ} \mathrm{C} / \mathrm{min}$ and $4.2^{\circ} \mathrm{C} / \mathrm{min}$, respectively. The samples sintered were grinded to $2 \mathrm{~mm}$ thickness with a grinding machine (Autoron mini, Maruto). Relative density of the samples obtained were measured as more than $96 \%$ based on Archimedes method.

Both samples were polished with diamond slurry $(9$ and $3 \mu \mathrm{m})$ and buffed with alumina slurry $(0.03 \mu \mathrm{m})$. Surface roughness was less than $0.3 \mu \mathrm{m}$. The samples for mechanical testing were cut into rectangular specimens of $18 \mathrm{~mm}$ long $\times 2.0 \mathrm{~mm}$ wide $\times 1.5 \mathrm{~mm}$ thick. The tensile surface in bending test as mentioned below was also polished. Finally, the corners of specimens were chamfered with an emery paper. After polishing, all samples were ultrasonically washed in a bath filled with acetone for $15 \mathrm{~min}$. After that, the specimens were dried in a vacuum chamber at the temperature of 115 ${ }^{\circ} \mathrm{C}$ for 2 hours. 


\subsection{Ion irradiation}

The sample surfaces were irradiated using calcium $(\mathrm{Ca})$ or magnesium $(\mathrm{Mg})$ ions with an implanter (IMX-3500, ULVAC). For generation of $\mathrm{Ca}$ and $\mathrm{Mg}$ ion beams, evaporated calcium nitrate tetrahydrate and pure magnesium at about $520{ }^{\circ} \mathrm{C}$ were used as feeds to the ion sources, respectively. The ion-beams were mass analyzed and selected to yield the singly charged $\mathrm{Ca}$ or $\mathrm{Mg}$ ions for implantation. The typical ion beam current density was $3-4 \mu \mathrm{A} / \mathrm{cm}^{2}$. Target chamber pressure was 1.0 to $2.0 \times 10^{-5} \mathrm{~Pa}$. The pumping systems for process chamber were a combination of a rotary pump with a turbo pump.

Ca ion was irradiated at different ion dose, $1.0 \times 10^{12} \sim 10^{16} \mathrm{ions} / \mathrm{cm}^{2}$, with same accelerating voltage $60 \mathrm{keV}$ for comparison by ion irradiation dose. In addition, for comparison by ion projected depth, Ca ion was also irradiated at same ion dose $1.0 \times 10^{12} \mathrm{ions} / \mathrm{cm}^{2}$ with different accelerating voltage, 30,60 and $120 \mathrm{keV}$, which correspond to the depth, 35 , 70 and $140 \mathrm{~nm}$ calculated using TRIM code (Ziegler et al. 1985), respectively. Mg ion was irradiated at different ion dose, $1.0 \times 10^{13}, 10^{15}$ and $10^{16}$, with same accelerating voltage of $30 \mathrm{keV}$. For the bending samples, Ca ion was irradiated only on the tensile surface in bending test at ion dose $1.0 \times 10^{14}$ ions $/ \mathrm{cm}^{2}$ with accelerating voltage $60 \mathrm{keV}$.

In order to clarify the ion irradiation on surface electrical potential, ion irradiation was conducted on specimens half area of whose surface was masked with Teflon tape. After irradiation, the difference in the surface potential of specimen was scanned with an atomic force microscope (AFM, Dimension Icon, Bruker). The type of cantilever is standard rectangular made of pure silicon. Scan was conducted two times.

\subsection{Characterization of in-vitro bioactivity}

Bioactivity of HA was investigated by soaking the samples in simulated body fluid (SBF). SBF was proposed by Kokubo to evaluate the bioactivity in vitro (Kokubo 1991). SBF has a similar ion concentration with human blood plasma. SBF was prepared by dissolving the reagent-grade chemicals, as shown in Table 1, into distilled water in order and buffered with Tris and $\mathrm{HCl}$ to $\mathrm{pH} 7.4$ at $37^{\circ} \mathrm{C}$. Specimens were immersed in $\mathrm{SBF}$ at $37^{\circ} \mathrm{C}$ for a certain period. The HA irradiated with $\mathrm{Ca}$ ion at different ion dose was immersed for 1 day and 1 week. The HA irradiated with Ca ion at different ion irradiation depth and $\mathrm{Mg}$ ion was immersed for 3 days. After immersion to SBF, the surface of specimens was observed with a scanning electron microscope (SEM, S-3700N, Hitachi) equipped with an energy dispersive spectrometer (EDS, Oxford INCAxact) to confirm bone-like apatite formation. Apatite layer thickness was measured by observing the surface cross-section cutting using focused ion beam (FIB). From the cross-sectional observation, the surface profile was obtained and the average thickness was calculated. The observation was conducted on 5 cross-section at least. Bioactivity of HA was evaluated with the thickness observations.

Table 1 The composition of chemicals for SBF preparation.

\begin{tabular}{c|l|l|l|l|c|c|c|c|c}
\hline Reagent & $\begin{array}{l}\mathrm{CaCl}_{2} \\
2 \mathrm{H}_{2} \mathrm{O}\end{array}$ & $\begin{array}{l}\mathrm{MgCl}_{2} \\
6 \mathrm{H}_{2} \mathrm{O}\end{array}$ & $\mathrm{Na}_{2} \mathrm{SO}_{4}$ & $\begin{array}{l}\mathrm{K}_{2} \mathrm{HPO}_{4} \cdot \\
3 \mathrm{H}_{2} \mathrm{O}\end{array}$ & $\mathrm{NaHCO}_{3}$ & $\mathrm{KCl}$ & $\mathrm{NaCl}$ & Tris & $\mathrm{HCl}$ \\
\hline Mass & $0.3676 \mathrm{~g}$ & $0.3048 \mathrm{~g}$ & $0.0710 \mathrm{~g}$ & $0.1742 \mathrm{~g}$ & $0.3528 \mathrm{~g}$ & $\begin{array}{c}0.2237 \\
\mathrm{~g}\end{array}$ & $\begin{array}{c}7.9950 \\
\mathrm{~g}\end{array}$ & $\begin{array}{c}6.0568 \\
\mathrm{~g}\end{array}$ & $\begin{array}{c}4.5 \mathrm{ml} \\
(\mathrm{pH}=7.4)\end{array}$ \\
\hline
\end{tabular}

\subsection{Characterization of strength}

In order to clarify the effect of ion implantation on the mechanical properties of HA, four point bending tests were conducted. Inner and outer spans were $l=3 \mathrm{~mm}$ and $L=9 \mathrm{~mm}$, respectively. The tests was conducted at a loading rate 0.1 $\mathrm{mm} / \mathrm{min}$ with universal testing machine (AG-5kN, Simadzu, Japan). A load cell (LUK-500N-P, Kyowa Instrument Co., Japan) was instrumented to monitor load during bending tests. Bending strength, $\sigma_{B}$ was calculated as

$$
\sigma_{B}=\frac{3 P(L-l)}{2 w t^{2}}
$$

where $P$ denotes maximum load and $w$ and $t$ are specimen width and thickness, respectively. The number of specimen for each condition was 20 at least.

\subsection{Cell proliferation}

The osteoblastic cell line, MC3T3-E1, was cultured in alpha MEM (Life technologies; USA) supplemented with 1glutamine, penicillin (100 units $/ \mathrm{mL}$ ), streptomycin $(100 \mu \mathrm{g} / \mathrm{mL}), 10 \%$ fetal bovine serum (FBS) and $2 \mathrm{mM} \mathrm{L}$-glutamine in a humidified incubator at 37 and 5\% $\mathrm{CO}_{2}$. The medium was changed twice per week and cells in the logarithmic 
growth phase were harvested with $0.25 \%$ trypsin-EDTA (Life technologies; USA). The cells were pelleted by centrifugation and then were removed by media. The cells suspended with fresh media were plated at a density of $5.1 \times 10^{4}$ cells $/ \mathrm{cm}^{2}$ on $\mathrm{HA}$ irradiated at $\mathrm{Ca}$ ion dose $1.0 \times 10^{13} \mathrm{ion} / \mathrm{cm}^{2}$ with accelerating voltage $60 \mathrm{keV}$ and without $\mathrm{Ca}$ ion irradiation. The cells were cultured up to reach $70 \%$ to $80 \%$ confluence in three days. The cells were observed phasecontrast microscope (OLYMPUS IX73; Japan). The sample number was 6 for each condition.

The MC3T3-E1 cell proliferation rate was estimated by using Cell Counting Kit-8 (Dojindo Laboratories, Japan) following the manufacturer's instructions. Optical density (OD) at $450 \mathrm{~nm}$ (formation of formazan) was measured using Sunrise microplate reader (Tecan; Switzerland) with Magellan software. Average values of cell proliferation were compared for statistical significance using the Student's t-test. $\mathrm{p}<0.05$ was considered as statistically significant.

\section{Results and discussion}

\subsection{Ca ion irradiation at different ion dose}

Figure 2 shows SEM photographs of the surface of HA irradiated at different $\mathrm{Ca}$ ion dose after 1 day exposure to SBF. The enlargement photo (right) corresponds to the surface of the precipitates. After 1 day immersion, bone-like apatite formed thinly on the surface at all ion irradiation condition. Precipitates on each surface seem to be precursors of apatite formation. Figure 3 shows SEM photographs of the surface after 1 week exposure to SBF. After 1 week immersion, acicular apatite formed over the entire surface. In each ion irradiation condition, apatite formation was similar from SEM observation.

The bone-like apatite layer thickness after 1 day immersion is shown in Fig. 4. The symbols and the error bars correspond to average and maximum and minimum values, respectively. The apatite thickness increased with ion dose and larger than that without ion irradiation. This result indicated apatite formation rate was increased with $\mathrm{Ca}$ ion irradiation. The bone-like apatite layer thickness after 1 week immersion is shown in Fig. 5. After 1 week, apatite formation increased with ion dose up to $1.0 \times 10^{14} \mathrm{ions} / \mathrm{cm}^{2}$, whereas decreased over ion dose $1.0 \times 10^{15} \mathrm{ions} / \mathrm{cm}^{2}$. Therefore the optimum ion dose to improve the bioactivity of HA is considered as $1.0 \times 10^{14} \mathrm{ions} / \mathrm{cm}^{2}$. Figure 6 shows $\mathrm{Ca} / \mathrm{P}$ ratio measured with EDS. Ca/P ratio was almost constant irrespective of ion dose and immersion period and the value is about 1.67 which corresponds with theoretical $\mathrm{Ca} / \mathrm{P}$ ratio for HA. This results indicated the layer formed on the HA is bonelike apatite.

Figure 7 shows the result of surface electrical potential measurements by AFM. Without ion irradiation, the surface potential of HA charged negatively. However, with $\mathrm{Ca}$ ion irradiation, the surface potential charged positively. From these result, the reason of increasing apatite formation rate could be deduced as follows. When the surface of HA was irradiated with $\mathrm{Ca}$ ion, the surface potential charged positively with $\mathrm{Ca}$ ion. This process could skip the first step shown in Fig. 1 in the bone-like apatite formation process and apatite formation rate was accelerated.

\subsection{Ca ion irradiation at different accelerating voltage}

Figure 8 shows SEM photographs of the surface of HA irradiated at different accelerating voltage after 3 days exposure to SBF. After 3 days immersion, acicular apatite formed over the entire surface in all conditions. In each ion irradiation condition, bone-like apatite formation was similar from SEM observation.

The result of measurements of apatite layer thickness after 3 days immersion is shown in Fig. 9. The symbols and the error bars correspond to average and maximum and minimum values, respectively. Apatite layer thickness increased with acceleration voltage, that is, ion projected depth. Apatite thickness of HA irradiated at accelerating voltage $30 \mathrm{keV}$ was similar to that without $\mathrm{Ca}$ ion irradiation. In the case of lower accelerating voltage, ion irradiation depth is lower and ion could not remain in the material and the effect of ion irradiation was limited. In the higher accelerating voltage, ion projected depth increased and $\mathrm{Ca}$ ion existed in the surface. In addition, the ion projected region became chemicallyunstable and ion dissolution into SBF increased with depth, which results in the acceleration of bone-like apatite formation. Thus, apatite formation showed differences comparing with higher accelerating voltage. From these results, bone-like apatite formation increased with ion irradiation depth. Ion irradiation is consisted of the addition of ions to inside of near the surface of the material. However, in the case of depth less than $30 \mathrm{~nm}$ from surface, the ion irradiation did not act on apatite formation. The accelerating voltage of more than $30 \mathrm{keV}$ is necessary for increasing apatite formation. 


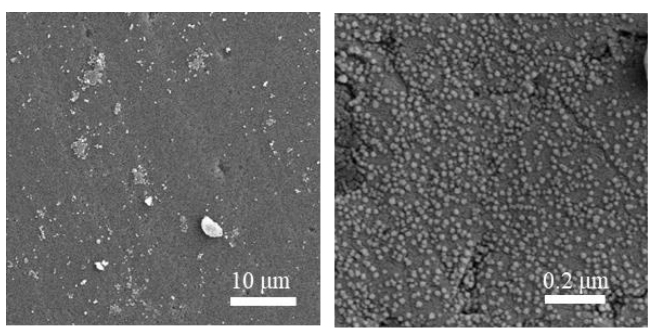

(a) without Irradiation

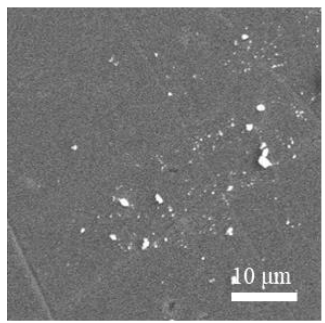

(b) Ca Ion $10^{12}$ ion $/ \mathrm{m}^{2}$

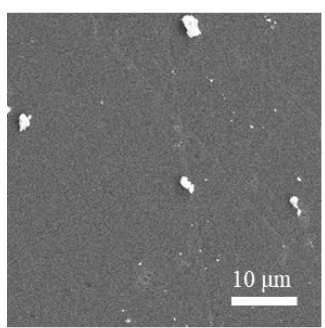

(c) Ca Ion $10^{13}$ ion $/ \mathrm{m}^{2}$
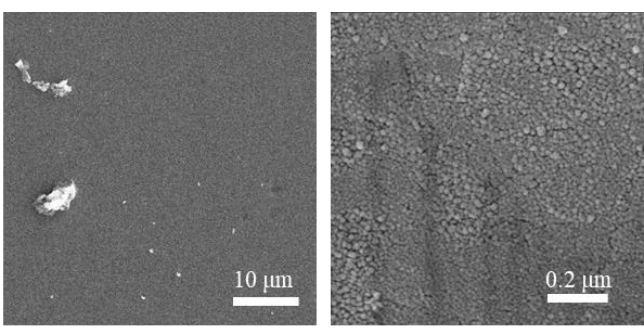

(d) Ca Ion $10^{14} \mathrm{ion} / \mathrm{m}^{2}$

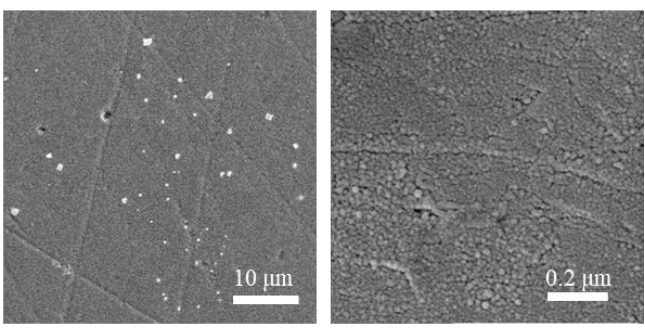

(e) Ca Ion $10^{15}$ ion $/ \mathrm{m}^{2}$

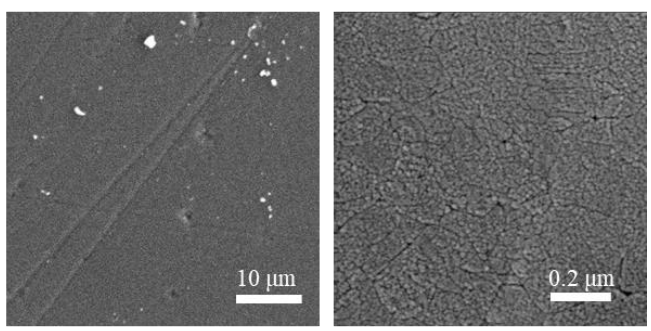

(f) Ca Ion $10^{16} \mathrm{ion} / \mathrm{m}^{2}$

Figure 2 Effect of $\mathrm{Ca}$ ion dose on the bone-like apatite formation after 1 day immersion in simulated body fluid.

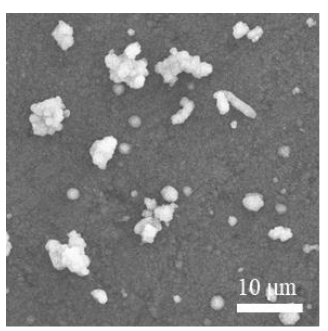

(a) without Irradiation

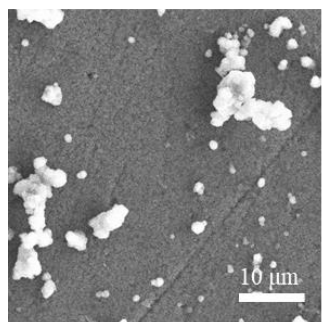

(b) Ca Ion $10^{12}$ ion $/ \mathrm{cm}^{2}$

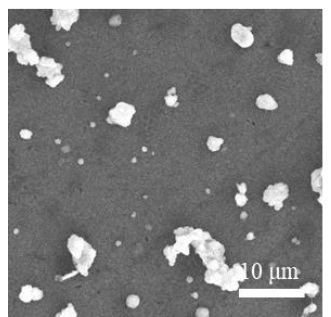

(c) Ca Ion $10^{13}$ ion $/ \mathrm{cm}^{2}$
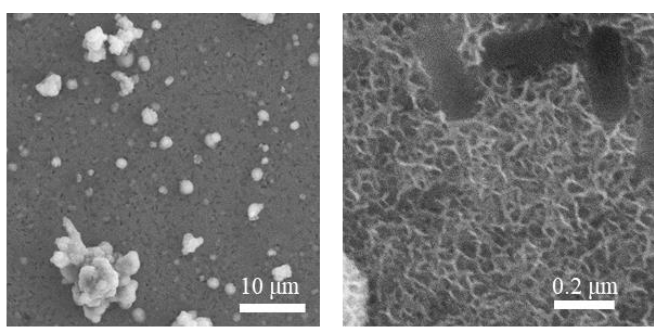

(d) Ca Ion $10^{14} \mathrm{ion} / \mathrm{cm}^{2}$

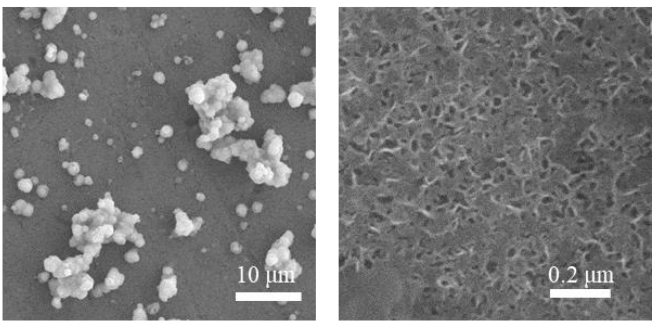

(e) Ca Ion $10^{15}$ ion $/ \mathrm{m}^{2}$
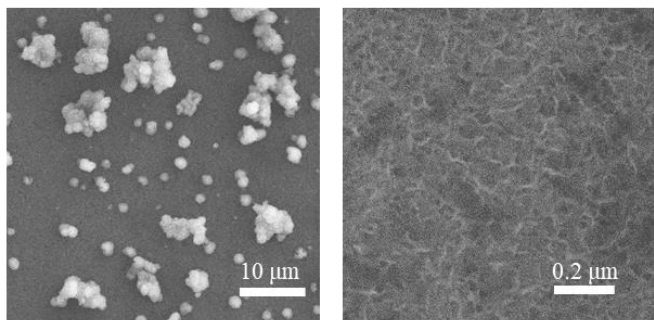

(f) Ca Ion $10^{16} \mathrm{ion} / \mathrm{cm}^{2}$

Figure 3 Effect of $\mathrm{Ca}$ ion dose on the bone-like apatite formation after 1 week immersion in simulated body fluid. 


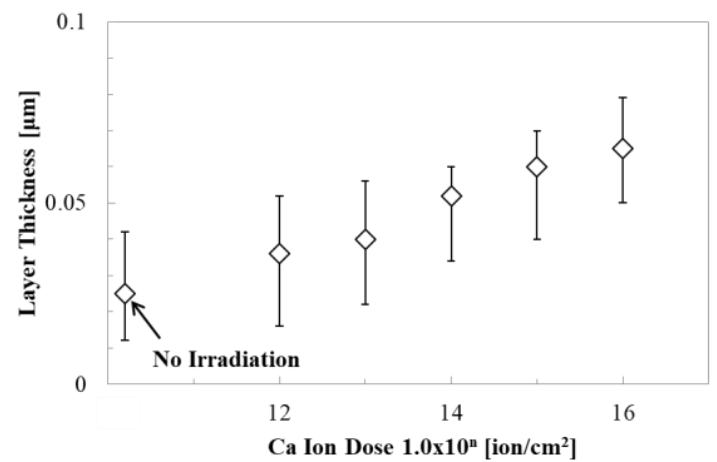

Figure 4 Effect of $\mathrm{Ca}$ ion dose on the bone-like apatite layer thickness after 1 day immersion in simulated body fluid.

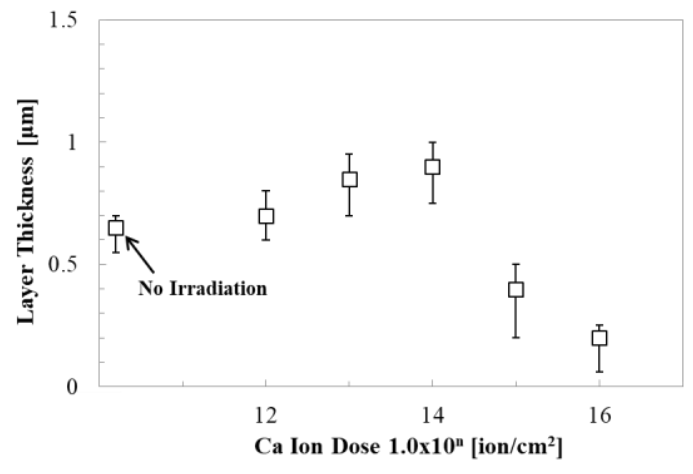

Figure 5 Effect of $\mathrm{Ca}$ ion dose on the bone-like apatite layer thickness after 1 week immersion in simulated body fluid.

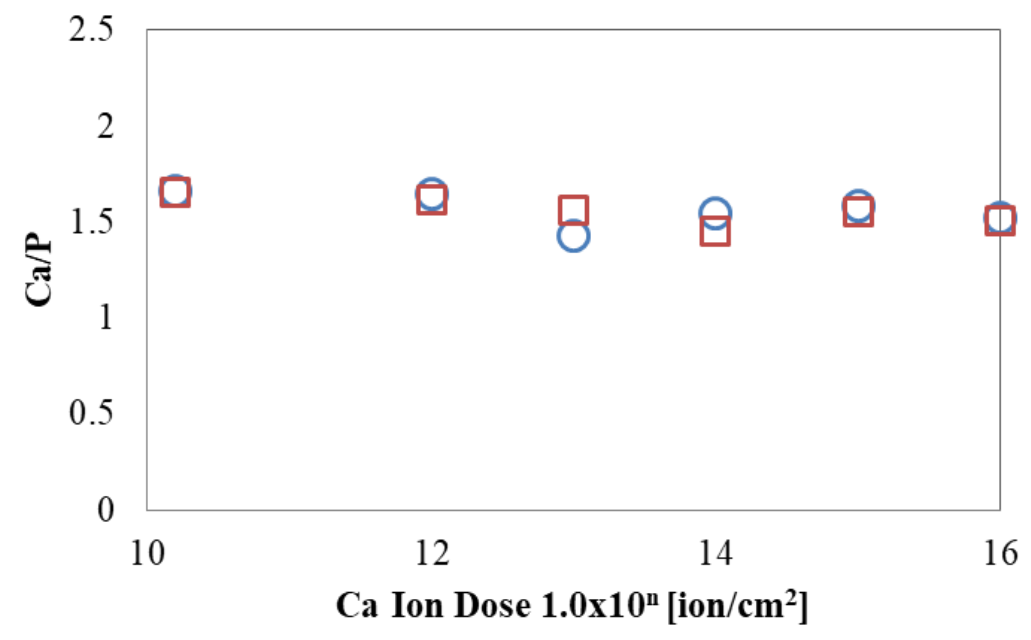

Figure 6 Effect of $\mathrm{Ca}$ ion dose on the $\mathrm{Ca} / \mathrm{P}$ ratio for the bone-like apatite layer.

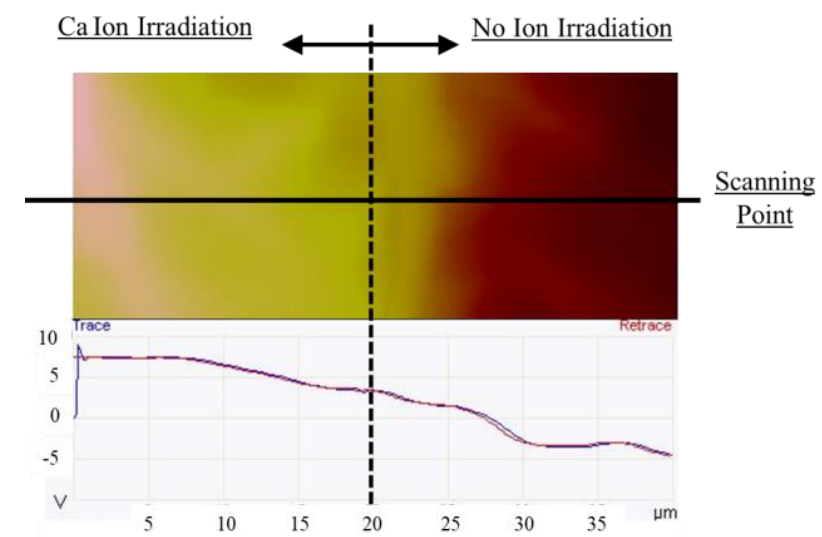

Figure 7 Surface potential of HA surface irradiated at Ca ion dose $10 \times 10^{16} \mathrm{ions} / \mathrm{cm}^{2}$. 


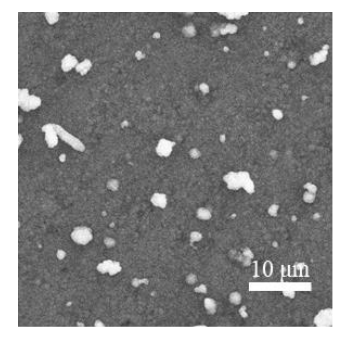

(a) without Ca irradiation

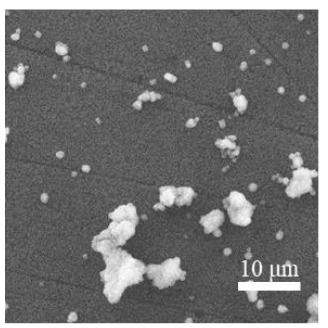

(b) Accelerating voltage $30 \mathrm{keV}$

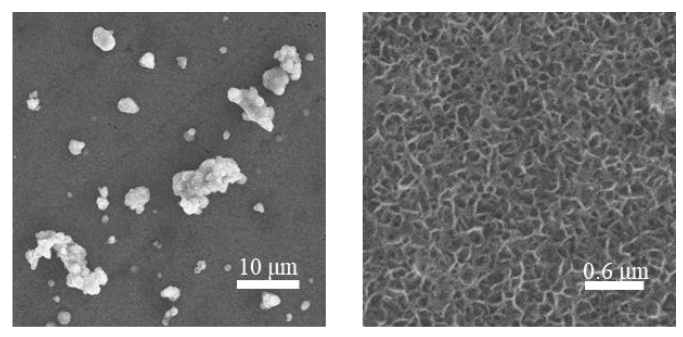

(c) Accelerating voltage $60 \mathrm{keV}$
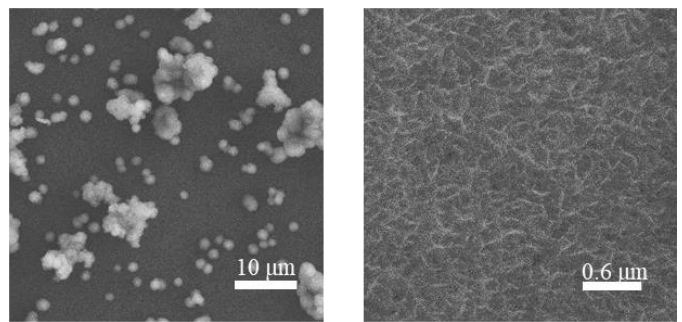

(d) Accelerating voltage $120 \mathrm{keV}$

Figure 8 Effect of accelerating voltage on the bone-like apatite formation after 3 days immersion in simulated body fluid (Ca ion irradiation).

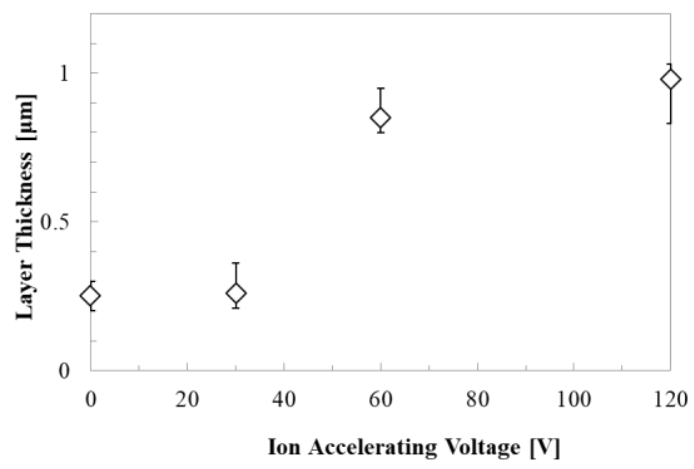

Figure 9 Effect of accelerating voltage on the bone-like apatite layer thickness after 3 day immersion in simulated body fluid (Ca ion irradiation).

\subsection{Mg ion irradiation at different ion dose}

Figure 10 shows SEM photographs of the surface of HA irradiated at different $\mathrm{Mg}$ ion dose after 3 days exposure to SBF. After 3 days immersion, the apatite formation of HA irradiated at ion dose $1.0 \times 10^{13}$ ions $/ \mathrm{cm}^{2}$ was similar to the case of no ion irradiation. Acicular apatite formation was also observed for the HA irradiated at ion dose $1.0 \times 10^{15}$ ions $/ \mathrm{cm}^{2}$, however the amount of apatite became lower than without $\mathrm{Mg}$ ion irradiation. At ion dose $1.0 \times 10^{16} \mathrm{ions} / \mathrm{cm}^{2}$, the apatite formation was severely inhibited. This fact indicated that the bioactivity of $\mathrm{HA}$ irradiated with Mg ion decreased with ion dose.

Figure 11 shows the result of surface potential measurement by AFM. Without $\mathrm{Mg}$ ion irradiation, the surface potential of HA charged negatively. After Mg ion irradiation, the surface potential charged more negatively. This result is opposite to the case of $\mathrm{Ca}$ ion irradiation. Thus, induction time for the first process of bone-like apatite formation, as shown in Fig. 1, was increased. As a result, apatite formation rate was decreased. From these results, Mg ion irradiation is not effective for improvement in apatite formation. 

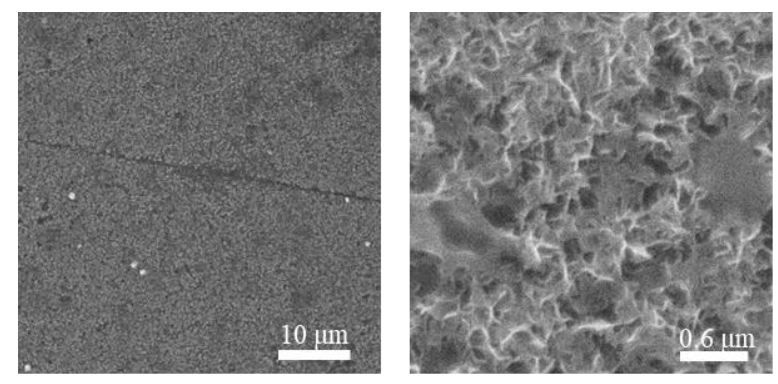

(a) without Mg irradiation
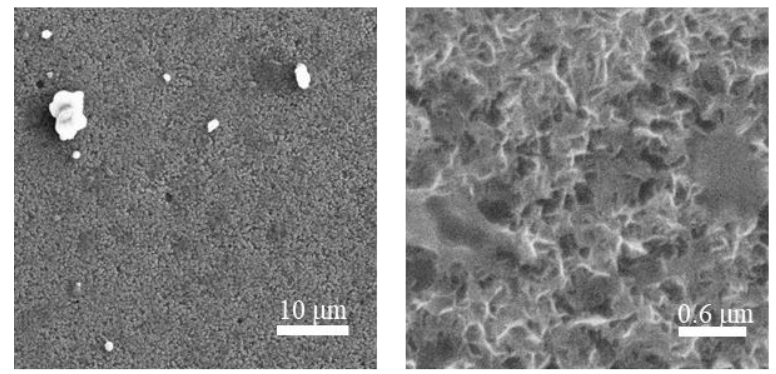

(b) $\mathrm{Mg}$ Ion $10^{13} \mathrm{ion} / \mathrm{cm}^{2}$
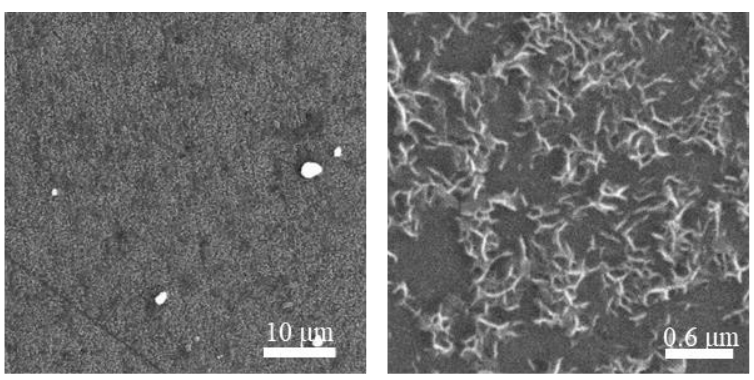

(c) $\mathrm{Mg}$ Ion $10^{15} \mathrm{ion} / \mathrm{cm}^{2}$
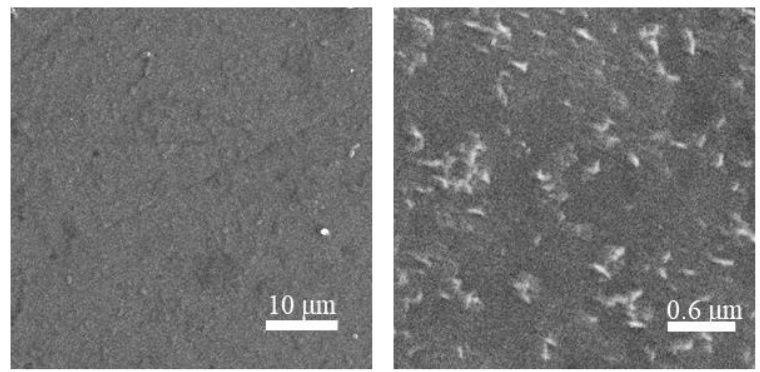

(d) $\mathrm{Mg}$ Ion $10^{16} \mathrm{ion} / \mathrm{cm}^{2}$

Figure 10 Effect of $\mathrm{Mg}$ ion dose on the bone-like apatite formation after 3 days immersion in simulated body fluid.

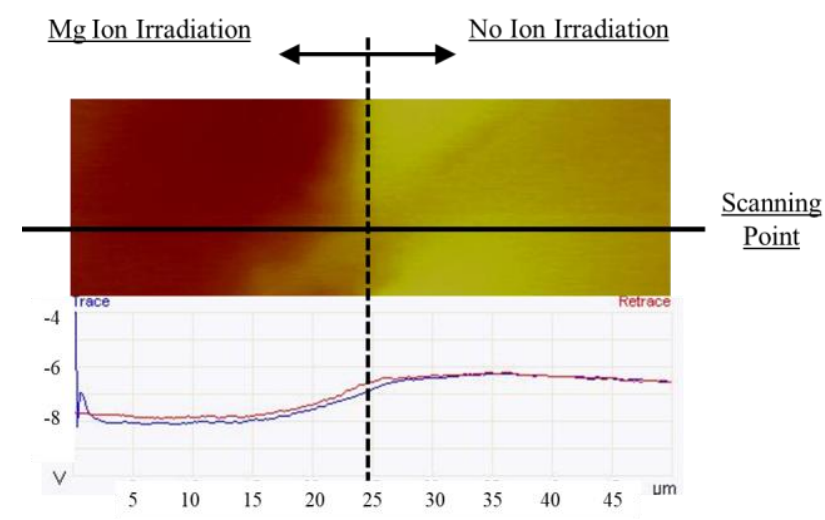

Figure 11 Surface potential of HA surface irradiated at Mg ion dose $10 \times 10^{16}$ ions $/ \mathrm{cm}^{2}$.

\subsection{Effect of ion irradiation on bending strength}

The effect of exposure to SBF on the bending strength of HA with and without Ca ion irradiation is shown in Fig. 12. The symbols and the error bars correspond to average and maximum and minimum values, respectively. Bending strength slightly decreased with $\mathrm{Ca}$ ion irradiation before immersion. This is a similar result with $\mathrm{P}$ ion irradiation (Kobayashi et al 2015) and is due to nano-sized damage induced by ion irradiation. After 1 day immersion. strength significantly decreased for both samples. After that, strength was gradually recovered with exposure time and became same level with the initial state. On the surface of HA, invertible dissolution reaction occurred and the ion dissolved and pre-included in SBF were used for bone-like apatite formation. Decreasing strength after 1 day and strength recovery were due to surface dissolution and bone-like apatite formation. From t-test results considering p $<0.05$, results show no statistically significant between with and without $\mathrm{Ca}$ ion irradiation. Therefore strength reduction after 1 day caused by Ca ion irradiation is negligible up to ion dose $1.0 \times 10^{14}$ ions $/ \mathrm{cm}^{2}$. 


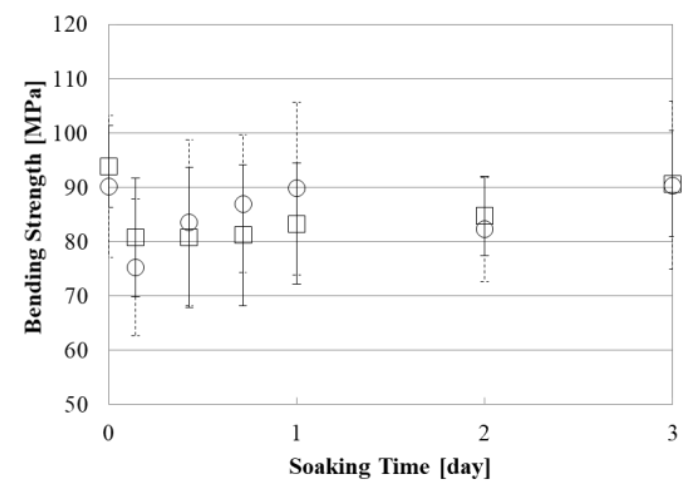

Figure 12 Effect of exposure to simulated body fluid on the bending strength of HA with and without Ca ion irradiation (Ca ion dose $10 \times 10^{14}$ ions $/ \mathrm{cm}^{2}$ and accelerating voltage $60 \mathrm{keV}$ ).

\subsection{Cell proliferation}

The morphological changes observed in MC3T3-E1 on HA with and without Ca ion is shown in Figure 13. Alterations in the morphology of the cell were not found by irradiation of ions. The OD450 (or number) of the cells observed by using Cell Counting Kit-8 as assay are shown in Figure 14. The error bars corresponds to standard deviation. Result shows no statistically significant between $\mathrm{HA}$ with and without $\mathrm{Ca}$ ion. This results suggests $\mathrm{Ca}$ ion irradiation has no toxicity for cell proliferation and the possibility of the $\mathrm{Ca}$ ion irradiation for bone formation in the body was confirmed. Cohen's d value were also calculated and obtained as 0.71 and 1.56 for 1 day and 3 days, respectively. Therefore it was concluded that the effect size are larger with ion irradiation.

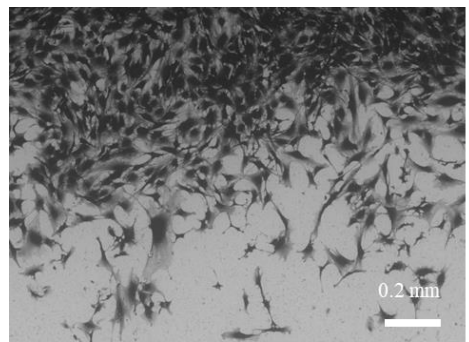

(a-1) HA without Ca Ion, After 1 Day

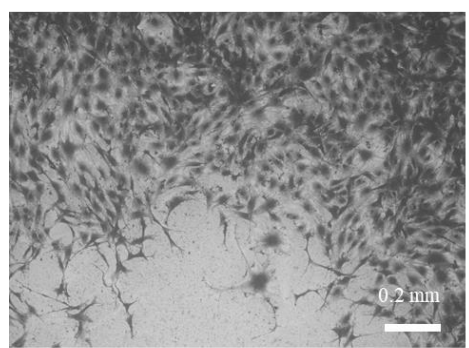

(a-2) HA without Ca Ion, After 3 Days

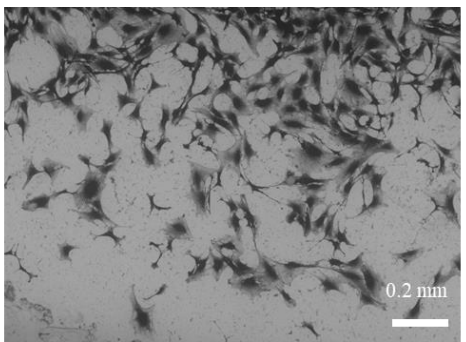

(b-1) HA with Ca Ion, After 1 Day

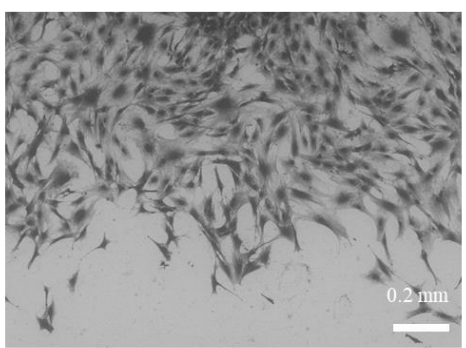

(b-2) HA with Ca Ion, After 3 Days

Figure 13 Morphology of the cell cultured on HA with and without $\mathrm{Ca}$ ion irradiation $\left(\mathrm{Ca}\right.$ ion dose $10 \times 10^{14}$ ions $/ \mathrm{cm}^{2}$ and accelerating voltage $60 \mathrm{keV}$ ). 


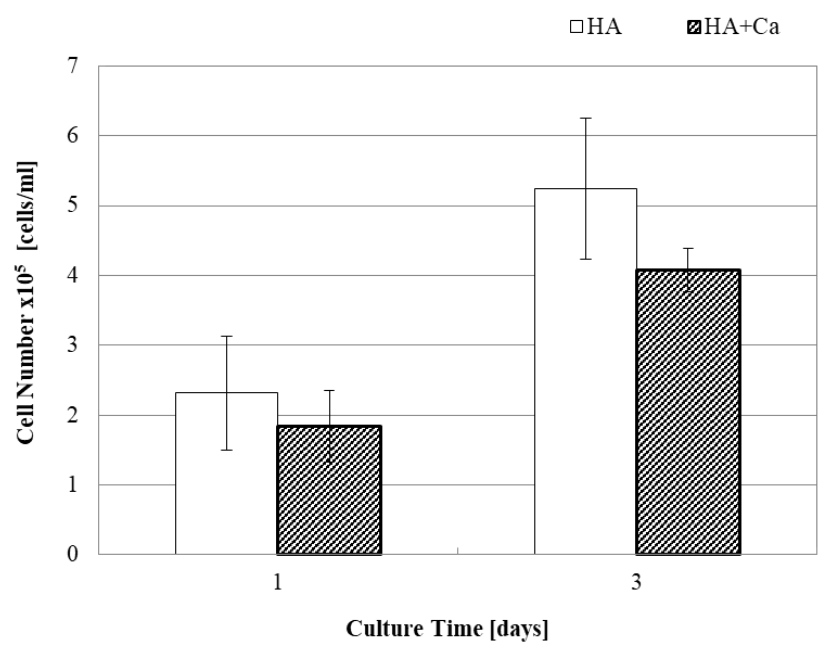

Figure 14 Cell number of HA and HA+Ca after 1 day and 3 days.

\section{Conclusion}

In the present study, $\mathrm{Ca}$ and $\mathrm{Mg}$ ions were irradiated to improve bioactivity of $\mathrm{HA}$. Ca ion irradiation improve bonelike apatite formation on the surface of HA, whereas successive ion dose inhibited bone-like apatite growth. In order to improve bone-like apatite formation, the accelerating voltage more than $30 \mathrm{keV}$ is necessary. With Mg ion irradiation, bone-like apatite formation was not improved. The difference in the effect of ion irradiation was attributed to the surface electrical potential of HA. From bending tests, strength reduction caused by $\mathrm{Ca}$ ion irradiation was negligible comparing to HA without ion irradiation. It is also indicated that there were no significant differences in cell proliferation on HA with and without $\mathrm{Ca}$ ion irradiation. These results suggested that $\mathrm{Ca}$ ion irradiation at optimum ion dose and depth is appropriate method to improve bioactivity of HA without reduction in mechanical properties.

\section{References}

Jaskierowicz, G., Dunlop, A. and Jonckheere, R., Track formation in fluorapatite irradiated with energetic cluster ions, Nuclear Instruments and Method in Physics Research B, Vol.222 (2004), pp. 213-227.

Kim, H-M., Himeno, T., Kokubo, T. and Nakamura, T., Process and kinetics of bonelike apatite formation on sintered hydroxyapatite in a simulated body fluid, Biomaterials, Vol.26 (2005), pp. 4366-4373.

Kobayashi, S., Muramatsu, T. and Teranishi, Y., Effect of phosphorous ion implantation on the mechanical properties and bioactivity of hydroxyapatite, Journal of Materials Science: Materials in Medicine, Vol.26 (2015) (online) DOI: $10.1007 / \mathrm{s} 10856-014-5351-9$.

Kobayashi, S., and Murakoshi, T., Effect of $\mathrm{MgO}$ addition on sintering of calcium phosphate ceramics and composites, Advanced Composite Materials, Vol.24 (2015), pp. 137-146.

Kokubo, T., Bioactive glass ceramics: properties and applications, Biomaterials, Vol.12 (1991), pp. 155-163.

Lopatin, C. M., Alford, T. L., Pizziconi, V. B., Kuan, M. and Laursen, T. , Lon-beam densification of hydroxyapatite thin films, Nuclear Instruments and Method in Physics Research B, Vol. 145 (1998), pp. 522-531.

Miro, S., Grebille, D., Chateigner, D., Pelloquin, D., Stoquert, J. -P., Grob, J.-J., Costantini, J.-M. and Studer, F., X-ray diffraction study of damage induced by swift heavy ion irradiation in fluorapatite, Nuclear Instruments and Method in Physics Research B, Vol.227 (2005), pp. 306-318.

Parthiban, S. P., Suganthi, R. V., Girija, E. K., Elayaraja, K., Kulriya, P. K., Katharria, Y. S., Singh, F., Sulania, I., Tripathi, A., Asokan, K., Kanjilal, D., Yadav, S., Singh, T. P., Yokogawa, Y. and Kalkura, S. N., Effect of heavy ion irradiation on hydrothermally synthesized hydroxyapatite ceramics, Nuclear Instruments and Method in Physics Research B, Vol.266 (2008), pp. 911-917.

Pelletier, H., Nelea, V., Mille, P. and Muller, D., Mechanical properties of pulsed laser-deposited hydroxyapatite thin film implanted at high energy with $\mathrm{N}+$ and $\mathrm{Ar}+$ ions. Part I: nanoindentation with spherical tipped indenter, Nuclear Instruments and Method in Physics Research B, Vol.216 (2004a), pp. 269-274.

Pelletier, H., Nelea, V., Mille, P. and Muller, D., Mechanical properties of pulsed laser-deposited hydroxyapatite thin film implanted at high energy with $\mathrm{N}+$ and $\mathrm{Ar}+$ ions. Part II: nano-scratch tests with with spherical tipped indenter, 
Kobayashi, Izawa, Teranishi and Ohyabu, Journal of Biomechanical Science and Engineering, Vol.13, No.3 (2018)

Nuclear Instruments and Method in Physics Research B, Vol.216 (2004b), pp. 275-280.

Ziegler, J. F., Biersack, J. P. and Littmark, U., The Stopping and Ranges of Ions in Solids. Sopping and Range of Ions in Matter Vol. 1. (1985), Oxford: Pergamon. 